\title{
Granules for Oral Solution Dosage Form
}

National Cancer Institute

\section{Source}

National Cancer Institute. Granules for Oral Solution Dosage Form. NCI Thesaurus. Code C149546.

Solid preparation consisting of aggregated particles that may include excipients to facilitate wetting and dissolution, intended to be dissolved in the specified liquid to obtain an oral solution, which is usually prepared just before administration to the patient. 